\title{
Acute aortic dissections with entry tear in the arch: A report from the International Registry of Acute Aortic Dissection
}

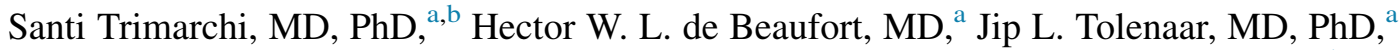

Joseph E. Bavaria, MD, ${ }^{\mathrm{c}}$ Nimesh D. Desai, MD, PhD,${ }^{\mathrm{c}}$ Marco Di Eusanio, MD, PhD, ${ }^{\mathrm{d}}$

Roberto Di Bartolomeo, MD, ${ }^{\mathrm{e}}$ Mark D. Peterson, MD, PhD, ${ }^{\mathrm{f}}$ Marek Ehrlich, MD, ${ }^{\mathrm{g}}$

Arturo Evangelista, MD, ${ }^{\mathrm{h}}$ Daniel G. Montgomery, BS, ${ }^{\mathrm{i}}$ Truls Myrmel, MD, PhD, ${ }^{\mathrm{j}}$ G. Chad Hughes, MD,

Jehangir J. Appoo, MD, ${ }^{1}$ Carlo De Vincentiis, MD, ${ }^{\mathrm{a}}$ Tristan D. Yan, MD, $\mathrm{PhD},{ }^{\mathrm{m}}$

Christoph A. Nienaber, MD, PhD, ${ }^{\mathrm{n}}$ Eric M. Isselbacher, MD, ${ }^{\circ}$ G. Michael Deeb, MD, ${ }^{\mathrm{P}}$

Thomas G. Gleason, MD, ${ }^{\mathrm{q}}$ Himanshu J. Patel, MD, ${ }^{\mathrm{p}}$ Thoralf M. Sundt, MD, ${ }^{\mathrm{r}}$ and Kim A. Eagle, MD

\section{ABSTRACT}

Objective: To analyze presentation, management, and outcomes of acute aortic dissections with proximal entry tear in the arch.

Methods: Patients enrolled in the International Registry of Acute Aortic Dissection and entry tear in the arch were classified into 2 groups: arch A (retrograde extension into the ascending aorta with or without antegrade extension) and arch B (only antegrade extension into the descending aorta or further distally). Presentation, management, and in-hospital outcomes of the 2 groups were compared.

Results: The arch A $(\mathrm{n}=228)$ and arch B $(\mathrm{n}=140)$ groups were similar concerning the presence of any preoperative complication $(68.4 \%$ vs $60.0 \% ; P=.115)$, but the types of complication were different. Arch A presented more commonly with shock, neurologic complications, cardiac tamponade, and grade 3 or 4 aortic valve insufficiency and less frequently with refractory hypertension, visceral ischemia, extension of dissection, and aortic rupture. Management for both groups were open surgery $(77.6 \%$ vs $18.6 \% ; P<.001)$, endovascular treatment $(3.5 \%$ vs $25.0 \% ; P<.001)$, and medical management $(16.2 \%$ vs $51.4 \%$; $P<.001)$. Overall in-hospital mortality was similar $(16.7 \%$ vs $19.3 \%$; $P=.574)$, but mortality tended to be lower in the arch A group after open surgery $(15.3 \%$ vs $30.8 \% ; P=.090)$, and higher after endovascular $(25.0 \%$ vs $14.3 \%$; $P=.597)$ or medical treatment $(24.3 \%$ vs $13.9 \% ; P=.191)$, although the differences were not significant.

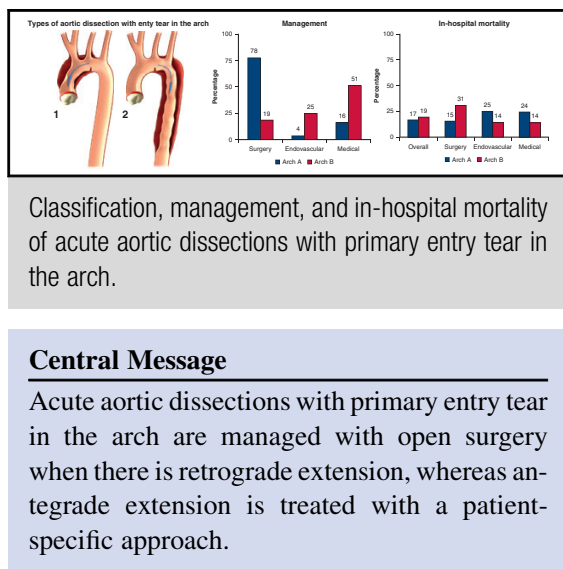

\section{Perspective}

Although current guidelines suggest surgical repair for all acute aortic arch dissections, in current practice only those dissections with retrograde extension into the ascending aorta are commonly treated with open surgery, whereas arch dissections with extension into the descending aorta and no ascending involvement are treated endovascularly or medically, if uncomplicated.

See Editorial Commentary page 74 .

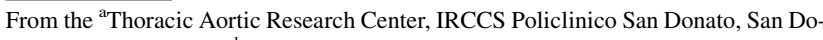
nato Milanese, Italy; ${ }^{\mathrm{b}}$ Department of Scienze Biomediche per la Salute, University of Milan, Milan, Italy; ${ }^{c}$ Division of Cardiovascular Surgery, Hospital of the University of Pennsylvania, Philadelphia, Pa; ${ }^{\mathrm{d}}$ Department of Cardiac Surgery, Ospedali Riuniti di Ancona, Ancona, Italy; ${ }^{\mathrm{e}}$ Department of Cardiac Surgery, S. Orsola-Malpighi Hospital, University of Bologna, Bologna, Italy; ${ }^{\mathrm{f}}$ Division of Cardiac Surgery, St Michael's Hospital, Toronto, Ontario, Canada; ${ }^{\mathrm{g}}$ Department of Cardiothoracic Surgery, University of Vienna, Vienna, Austria; ${ }^{\mathrm{h}}$ Department of Cardiology, Hospital General Universitari Vall d'Hebron, Barcelona, Spain; Departments of ${ }^{\mathrm{i}}$ Medicine, and ${ }^{\mathrm{P}}$ Cardiac Surgery, Frankel Cardiovascular Center, University of Michigan, Ann Arbor, Mich; ${ }^{\mathrm{j} D e p a r t m e n t}$ of Thoracic and Cardiovascular Surgery, University of Troms $\emptyset$, Troms $\emptyset$, Norway; ${ }^{\mathrm{k}}$ Department of Surgery, Duke University Medical Center, Durham, NC; ${ }^{\mathrm{l} D i v i s i o n}$ of Cardiac Surgery, Libin Cardiovascular Institute, University of Calgary, Calgary, Alberta, Canada; ${ }^{\mathrm{m}}$ Department of Cardiothoracic Surgery, Royal Prince Alfred Hospital, University of Sydney, Sydney, Australia; ${ }^{\text {n}}$ Cardiology and Aortic Centre, Royal Brompton Hospital, Royal Brompton \& Harefield NHS Trust, Imperial College London, London, United Kingdom; ${ }^{\circ}$ Thoracic Aortic Center and Cardiology Division and ${ }^{\mathrm{r}}$ Division of Cardiac Surgery, Department of Surgery, Massachusetts General Hospital and Harvard Medical School, Boston, Mass; and ${ }^{\mathrm{q}}$ Division of Cardiac
Surgery, Department of Cardiothoracic Surgery, University of Pittsburgh School of Medicine, Pittsburgh, Pa.

The International Registry of Acute Aortic Dissection is supported by grants from Gore Medical Inc (Flagstaff, Ariz), Ann and Bob Aikens, the University of Michigan Health System, the Varbedian Fund for Aortic Research, the Mardigian Foundation, and Medtronic Inc (Minneapolis, Minn).

Read at The American Association for Thoracic Surgery Aortic Symposium 2018, New York, New York, April 26-27, 2018.

Dr Sant Trimarchi's current affiliation is Fondazione IRCCS Ca' Granda Ospedale Maggiore Policlinico, and Department of Scienze Biomediche per la Salute, University of Milan, Milan, Italy.

Received for publication March 1, 2018; revisions received July 3, 2018; accepted for publication July 19, 2018; available ahead of print Nov 2, 2018.

Address for reprints: Santi Trimarchi, MD, PhD, Thoracic Aortic Research Center, Policlinico San Donato IRCCS, University of Milan, Piazza Malan 2, 20097 San Donato Milanese, Italy (E-mail: santi.trimarchi@unimi.it).

$0022-5223 / \$ 36.00$

Copyright $(2018$ Published by Elsevier Inc. on behalf of The American Association for Thoracic Surgery

https://doi.org/10.1016/j.jtcvs.2018.07.101 


\section{Abbreviations and Acronyms \\ $\mathrm{AAD}=$ acute aortic dissection \\ $\mathrm{ET}=$ entry tear \\ IRAD $=$ International Registry of Acute Aortic Dissections}

Conclusions: Acute aortic dissection patients with primary entry tear in the arch are currently managed by a patientspecific approach. In choosing the management type of these patients, it may be advisable to stratify them based on retrograde or only antegrade extension of the dissection. (J Thorac Cardiovasc Surg 2019;157:66-73)

Optimal management of acute dissections generally depends on the location and extent of the dissection, and its associated complications. ${ }^{1-3}$ Currently, the most-used classification for acute dissection is the Stanford classification, in which Stanford type A refers to dissection involving the ascending aorta and the aortic arch, whereas Stanford type $\mathrm{B}$ refers to dissections confined to the descending aorta. ${ }^{2}$ Treatment of type A dissection typically requires immediate surgery, irrespective of the patient's clinical condition, whereas for type B dissection, endovascular or surgical methods are typically reserved for patients presenting with aortic aneurysms or clinical complications. ${ }^{2,4,5}$

For patients with acute aortic dissection (AAD) presenting with the proximal entry tear (ET) in the arch, most current guidelines suggest either surgical repair, or remain inconclusive on the optimal strategy. ${ }^{4,5}$ For AAD with arch ET and involvement of the ascending aorta, an aggressive surgical approach, even including total arch replacement in the acute setting, is usually preferred. ${ }^{6} \mathrm{How}-$ ever, when there is no ascending aorta involvement, "immediate surgery would be recommended by some, if feasible and the patient is viable, [whereas] others would select medical management if the patient has only an arch dissection without proximal extension, malperfusion, or bleeding, as long as repeat imaging demonstrates stability." ${ }^{5}$ In current practice, aortic centers frequently approach AAD with ET in the arch with medical therapy in the absence of ascending aorta involvement. Such patients, sometimes characterized as "non-A, non-B aortic dissection," 7 are treated as a type B dissection.

The International Registry of Acute Aortic Dissection (IRAD) was developed in 1996 to provide more insight into the presentation, management, and outcomes of acute dissection. ${ }^{8}$ After more than 20 years of enrolling patients, IRAD offers the opportunity to provide a comprehensive study of AAD with arch ET. The purpose of this study is to analyze treatment and outcomes of AAD with arch ET, comparing retrograde versus antegrade extension, to report current management, and to identify patterns in outcomes that may inform future practice.

\section{METHODS}

IRAD is an ongoing, multinational, multicenter registry that enrolls patients with AAD at 52 aortic centers. Its inception and structure has been described previously. ${ }^{6}$ Patient and procedure-related data were collected using forms with 290 variables that are submitted to the IRAD coordinating center at the University of Michigan and checked for face and analytical validity. Institutional review committees at all participating IRAD institutions approved the study and all subjects gave informed consent.

Patients with AAD were identified either prospectively at presentation or retrospectively by searching hospital discharge diagnosis records and/ or surgery, pathology, and imaging databases. The diagnosis was based on autopsy; surgical visualization; or imaging, which could be computed tomography, magnetic resonance imaging, or echocardiography. IRAD is an observational registry and the participating centers each have their own treatment strategy for patients with dissection; however, each participating center is an aortic center capable of offering the full range of surgical, endovascular, and medical treatment options.

For the present study, all patients enrolled in the registry from January 1996 through August 2017 were analyzed. Patients were excluded when data regarding ET location was not available or when multiple ETs were present. In addition, patients were excluded when data regarding the extent of the dissection was not reported. Based on the ET location and the extension of the dissection, patients were classified into 2 groups (Figure 1). The first group, arch A, consisted of patients with the ET in the aortic arch with retrograde extension into the ascending aorta with or without presence of antegrade extension (Figure 2). The second group, arch B, had an ET in the aortic arch, no ascending involvement, and antegrade extension into the descending and/or abdominal aorta, including those with isolated arch involvement (Figure 3 ). The 2 groups were compared regarding demographic characteristics, medical history, presence of complications at presentation, management, and in-hospital mortality. In-hospital mortality was defined as death during the initial hospitalization period for AAD.

\section{Statistical Analysis}

Data are shown as frequencies, percentages, mean \pm standard deviation, or median (25th-75th percentile). Both groups were compared using $\chi^{2}$ tests (or Fisher exact tests where appropriate) to analyze categorical variables. Student $t$ test was used to analyze continuous variables with a normal distribution, and nonparametric tests of medians were used to analyze nonnormally distributed categorical variables. Data analysis was performed by a statistician (DM) with the use of SPSS version 24.0 (IBM-SPSS Inc, Armonk, NY).

\section{RESULTS}

\section{Baseline Characteristics}

A total of 368 patients (248 men; mean age, 60.9 years) were included in this analysis (Figure 4). The arch A group consisted of 228 patients, the arch B group consisted of 140 patients. The 2 groups were not significantly different concerning demographic data or medical history (see Table 1). The median aortic diameter was typically larger at the level of the ascending aorta for arch A compared with arch B (4.7 vs $4.0 \mathrm{~cm} ; P<.001)$, although it was not significantly different at the level of the arch (3.8 vs $3.7 \mathrm{~cm} ; P=.605)$ or the descending aorta ( $3.5 \mathrm{vs} 3.7 \mathrm{~cm} ; P=.089$ ). The incidence of any preoperative complication was similar in the groups $(68.4 \%$ vs $60.0 \% ; P=.115)$ but the types of 


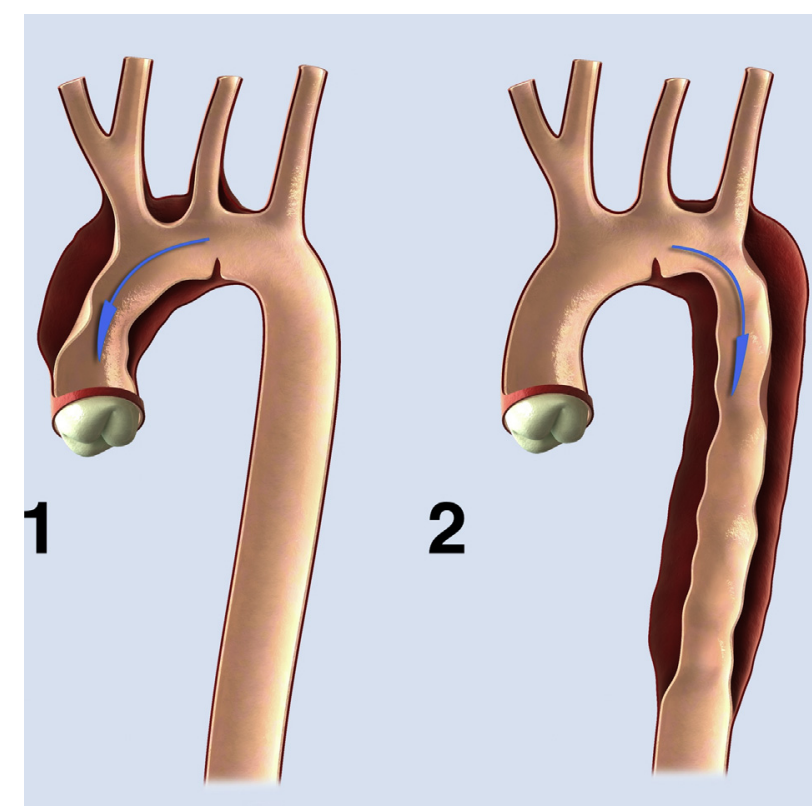

FIGURE 1. Acute aortic dissection with primary entry tear in the arch and retrograde extension into the ascending aorta, with or without extension into the descending aorta (arch A group, 1) or no ascending involvement and antegrade extension into the descending aorta or further distally (arch B group, 2).

complications were different (Table 1). The arch A group presented more commonly with shock $(30.7 \%$ vs $15.0 \%$; $P=.001)$, neurologic complications $(13.6 \%$ vs $5.7 \%$; $P=.022)$, cardiac tamponade $(13.2 \%$ vs $0.0 \%$; $P<.001)$, and grade 3 or 4 aortic valve insufficiency $(5.3 \%$ vs $0.7 \% ; P=.021)$ and less frequently with refractory hypertension $(0.0 \%$ vs $5.0 \% ; P=.001)$, visceral ischemia $(3.1 \%$ vs $12.9 \% ; P<.001)$, extension of dissection $(6.6 \%$ vs $14.3 \% ; P=.017)$, and aortic rupture $(0.4 \%$ vs $3.6 \% ; P=.032)$. Also, the time from diagnosis to intervention was significantly shorter in the arch A group (4.1 vs 20.0 hours; $P<.001$ ) (Table 1 ).

\section{Management and In-hospital Outcomes}

Open surgery was most frequently adopted for arch A group patients, whereas it was infrequently adopted for arch B group patients $(77.6 \%$ vs $18.6 \% ; P<.001)$. Endovascular treatment was used rarely for arch $\mathrm{A}$ patients, compared with a quarter of arch B patients $(3.5 \%$ vs $25.0 \% ; P<.001)$, and medical treatment only was employed in a small proportion of arch A patients and about half of arch B patients $(16.2 \%$ vs $51.4 \% ; P<.001)$. (Figure 5).

The presence of preoperative complications led to more frequent adoption of invasive management options. Within the arch A group, complicated preoperative status was present in $69.5 \%$ of patients treated with open surgery $(\mathrm{n}=177)$, compared with $100 \%$ in patients who underwent endovascular treatment $(\mathrm{n}=8)$, and $59.5 \%$ in patients who received medical therapy only $(\mathrm{n}=37)(P=.056)$. Within the arch B group, complicated preoperative status was present in $65.4 \%$ of patients treated with open surgery $(n=26)$ compared with $74.3 \%$ in patients who underwent endovascular treatment $(\mathrm{n}=35)$ and $48.6 \%$ in patients who received medical therapy only $(\mathrm{n}=72)(P=.031)$.

The overall in-hospital mortality was similar for both groups $(16.7 \%$ vs $19.3 \% ; P=.574)$. However, those patients treated surgically showed a trend toward a lower mortality rate in the arch A group compared with the arch B group $(15.3 \%$ vs $30.8 \% ; P=.090)$. Mortality after

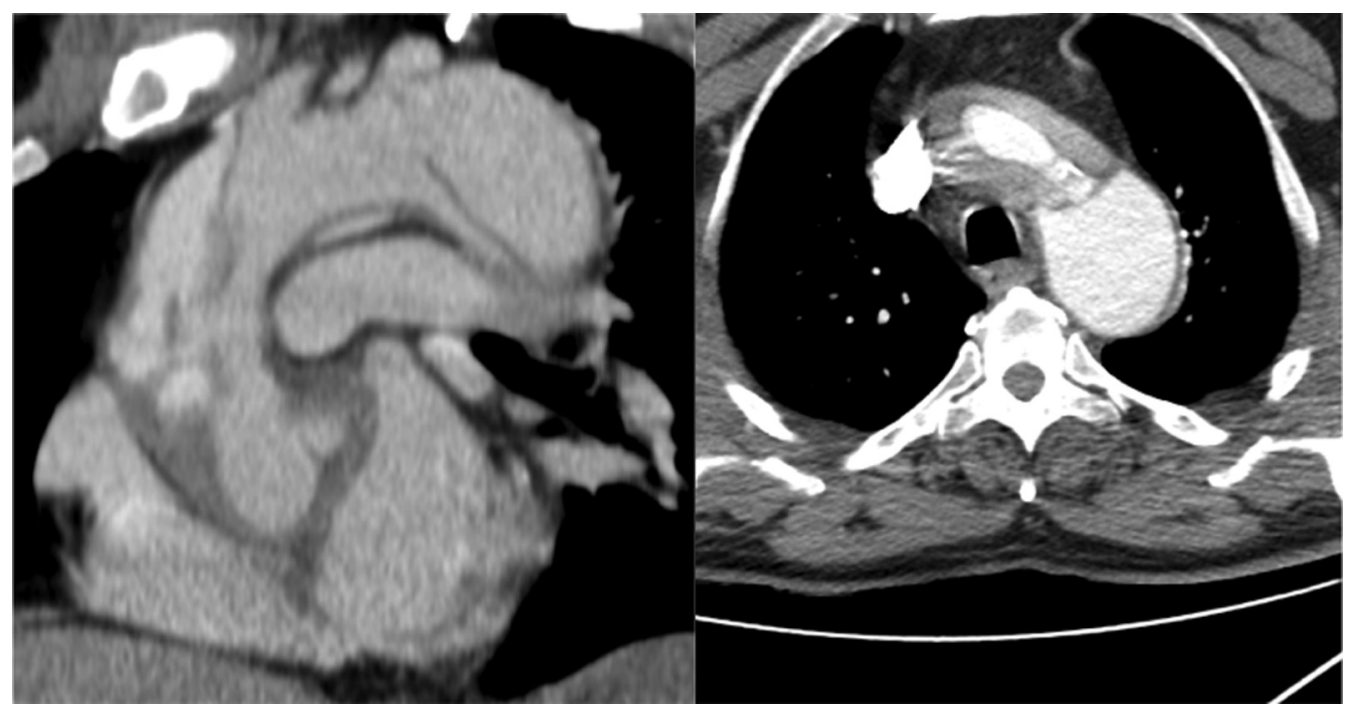

FIGURE 2. Computed tomography angiography scan of a patient with acute aortic dissection and primary entry tear between the innominate artery and the left common carotid artery with retrograde extension of dissection into the ascending aorta and antegrade extension into the descending aorta (arch A). 


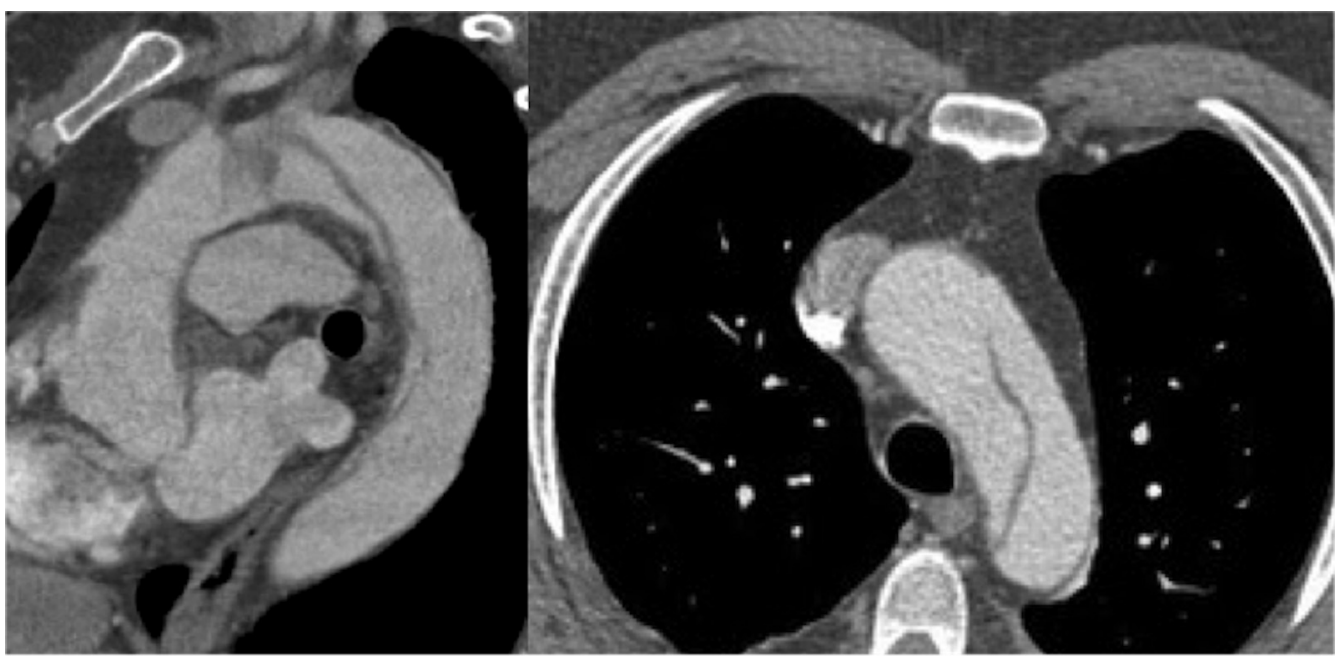

FIGURE 3. Computed tomography angiography scan of a patient with acute aortic dissection and primary entry tear between the origin of the innominate artery and the left common carotid artery and no ascending involvement (arch B).

endovascular or medical treatment were higher for arch A, although the difference was not significant $(25.0 \%$ vs $14.3 \% ; P=.597$ and $24.3 \%$ vs $13.9 \% ; P=.191$, respectively) (Figure 6). The causes of death were not significantly different for both groups (Table 2), although aortic rupture was more frequently reported as a cause of death for arch A patients $(26.3 \%$ vs $18.5 \% ; P=.462)$ and neurologic complications for arch B patients $(15.8 \%$ vs $29.6 \% ; P=.181)$. Antegrade or retrograde extension of dissection during the hospitalization period (preoperatively or when the patient was initially managed medically) occurred more frequently in arch B patients $(6.6 \%$ vs $13.8 \% ; P=.028)$.

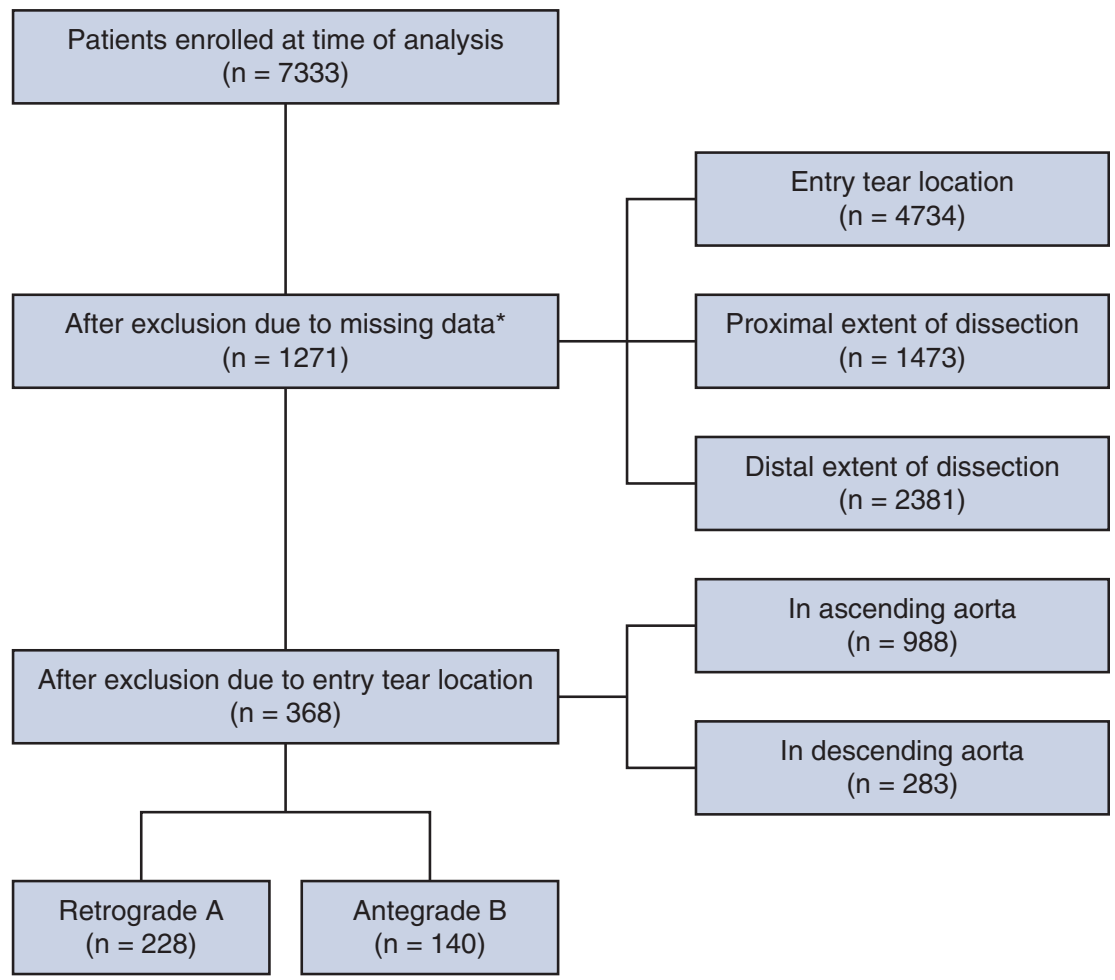

FIGURE 4. Flow chart describing numerically the number of patients excluded for each reason. *In some patients, there was more than 1 reason for exclusion. 
TABLE 1. Baseline characteristics of acute aortic dissections with primary entry tear in the arch

\begin{tabular}{|c|c|c|c|}
\hline & $\operatorname{Arch} \mathbf{A}$ & Arch B & $P$ value \\
\hline $\mathrm{N}$ & 228 & 140 & \\
\hline \multicolumn{4}{|l|}{ Demographic characteristics } \\
\hline Age (y) & $60.7 \pm 13.8$ & $61.3 \pm 13.7$ & .678 \\
\hline Female & $69(30.3)$ & $51(36.4)$ & .252 \\
\hline White race & $167(77.0)$ & $99(73.3)$ & .447 \\
\hline \multicolumn{4}{|l|}{ Medical history } \\
\hline Hypertension & $175(78.8)$ & $114(83.2)$ & .339 \\
\hline Atherosclerosis & $50(22.9)$ & $35(25.9)$ & .609 \\
\hline Diabetes & $13(6.0)$ & $12(8.8)$ & .394 \\
\hline Bicuspid aortic valve & $11(5.4)$ & $4(3.3)$ & .428 \\
\hline Marfan disease & $8(3.7)$ & $5(3.7)$ & 1.000 \\
\hline Renal insufficiency & $9(6.3)$ & $8(8.6)$ & .609 \\
\hline $\begin{array}{l}\text { Chronic obstructive } \\
\text { pulmonary disease }\end{array}$ & $11(7.7)$ & $9(9.8)$ & .635 \\
\hline \multicolumn{4}{|l|}{ Imaging } \\
\hline Ascending diameter $(\mathrm{cm})$ & $4.7(4.0-5.2)$ & $4.0(3.5-4.4)$ & $<.001$ \\
\hline Arch diameter $(\mathrm{cm})$ & $3.8(3.4-4.4)$ & $3.7(3.4-4.3)$ & .605 \\
\hline Descending diameter $(\mathrm{cm})$ & $3.5(3.0-4.0)$ & $3.7(3.3-4.3)$ & .089 \\
\hline \multicolumn{4}{|l|}{ Clinical status } \\
\hline Complicated & $156(68.4)$ & $84(60.0)$ & .115 \\
\hline Shock & $70(30.7)$ & $21(15.0)$ & .001 \\
\hline Spinal cord ischemia & $4(1.8)$ & $2(1.4)$ & 1.000 \\
\hline Coma & $30(13.2)$ & $12(8.6)$ & .237 \\
\hline Periaortic hematoma & $42(18.4)$ & $19(13.6)$ & .250 \\
\hline $\begin{array}{l}\text { Descending } \\
\quad \text { diameter }>5.5 \mathrm{~cm}\end{array}$ & $10(4.4)$ & $5(3.6)$ & .792 \\
\hline Refractory pain & $7(3.1)$ & $6(4.3)$ & .570 \\
\hline Refractory hypertension & $0(0.0)$ & $7(5.0)$ & .001 \\
\hline Limb ischemia & $22(9.6)$ & $14(10.0)$ & 1.000 \\
\hline Visceral ischemia & $7(3.1)$ & $18(12.9)$ & $<.001$ \\
\hline Extension of dissection & $15(6.6)$ & $20(14.3)$ & .017 \\
\hline Aortic rupture & $1(0.4)$ & $5(3.6)$ & .032 \\
\hline Acute renal failure & $16(7.0)$ & $15(10.7)$ & .248 \\
\hline Neurologic complication & $31(13.6)$ & $8(5.7)$ & .022 \\
\hline Cardiac tamponade & $30(13.2)$ & $0(0.0)$ & $<.001$ \\
\hline Congestive heart failure & $13(5.7)$ & $6(4.3)$ & .634 \\
\hline $\begin{array}{l}\text { Aortic insufficiency } \\
\text { grade } 3 \text { or } 4\end{array}$ & $12(5.3)$ & $1(0.7)$ & .021 \\
\hline $\begin{array}{l}\text { Myocardial } \\
\text { complication }\end{array}$ & $13(5.7)$ & $6(4.3)$ & .634 \\
\hline $\begin{array}{l}\text { Time from symptom onset to } \\
\text { diagnosis }(\mathrm{h})\end{array}$ & $4.5(2.7-12.0)$ & $4.8(2.7-10.2)$ & .806 \\
\hline $\begin{array}{l}\text { Time from diagnosis to } \\
\text { intervention (h) }\end{array}$ & $4.1(2.3-10.0)$ & $20.0(3.8-72.0)$ & $<.001$ \\
\hline
\end{tabular}

Values are presented as mean \pm standard deviation, $\mathrm{n} \mathrm{( \% ) \text {,ormedian(25th-75th }}$ percentile).

\section{DISCUSSION}

Treatment strategies for AAD patients with primary arch ET remain a subject of debate because contemporary classifications do not specifically stratify for these patients. This IRAD analysis shows that current practice differs

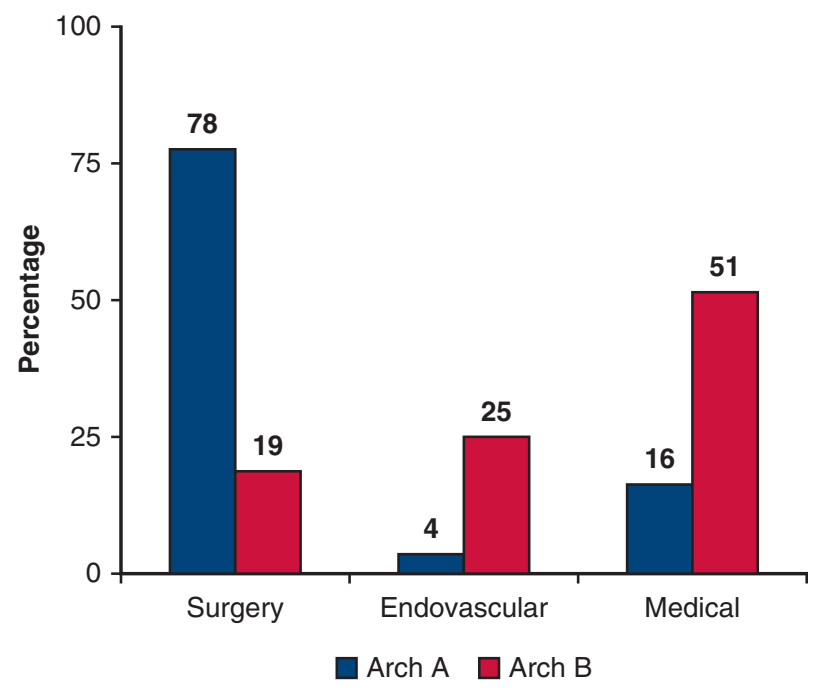

FIGURE 5. Management of acute aortic dissections with primary entry tear in the arch. The remaining $2.7 \%$ of patients in group 1 and $5.0 \%$ in group 2 were treated with hybrid surgical/endovascular methods.

from the recommendations, and that management and outcome of AAD is related to the extension of dissection. In particular, $\mathrm{AAD}$ with no ascending aorta involvement is not managed with open surgery in more than 4 out of 5 cases. A patient-specific approach appears to be preferred, depending on a patient's morphologic and clinical characteristics. Based on this observation, and due to the lack of a specific classification of AAD patients with proximal ET at the level of the arch, a new subcategorization of the Stanford classification might be considered as arch A, when the ascending is involved, and arch B when it is not.

Changes in surgical treatment and perioperative management have improved outcomes in arch dissection patients, but overall mortality remains high, $17.7 \%$ in this study,

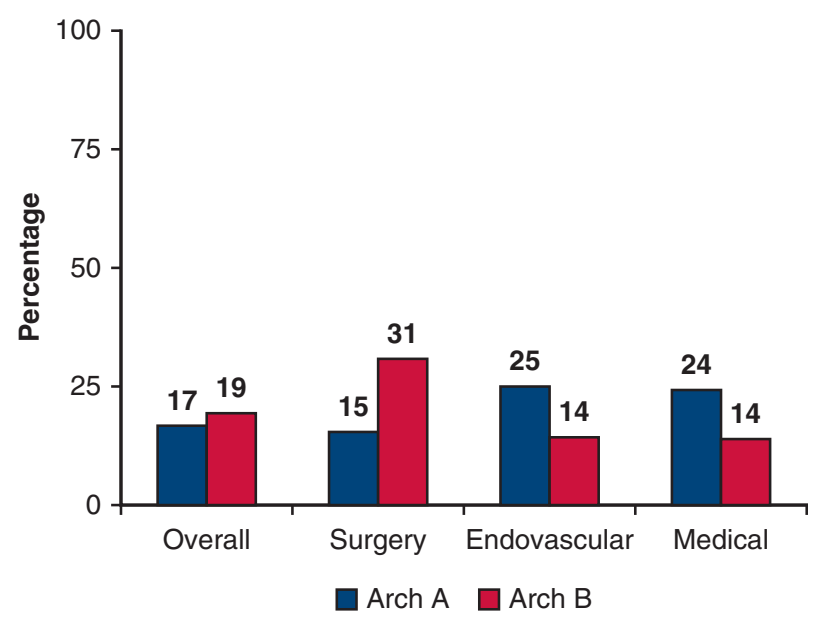

FIGURE 6. In-hospital mortality. Overall and by management type of acute aortic dissections with primary entry tear in the arch. 
TABLE 2. Causes of in-hospital death

\begin{tabular}{lccc}
\hline \multicolumn{1}{c}{ Cause } & $\begin{array}{c}\text { Arch A } \\
(\mathbf{n}=\mathbf{3 8})\end{array}$ & $\begin{array}{c}\text { Arch B } \\
(\mathbf{n}=\mathbf{2 7})\end{array}$ & $\boldsymbol{P}$ value \\
\hline Aortic rupture & $10(26.3)$ & $5(18.5)$ & .462 \\
Neurologic & $6(15.8)$ & $8(29.6)$ & .181 \\
Cardiac & $5(13.2)$ & $3(11.1)$ & .804 \\
Visceral ischemia & $5(13.2)$ & $2(7.4)$ & .461 \\
Major organ failure & $2(5.3)$ & $3(11.1)$ & .383 \\
Bleeding & $1(2.6)$ & $1(3.7)$ & .805 \\
Unspecified or unknown & $9(23.7)$ & $5(18.5)$ & .618 \\
\hline Values are presented as n (\%). & & &
\end{tabular}

which is comparable to the results of previous studies. ${ }^{9-11}$ The majority $(77.6 \%)$ of AAD patients with ascending aorta involvement (arch A) underwent surgical repair. Open surgery is the gold standard, and was associated with a lower in-hospital mortality rate compared with endovascular or medical treatment, respectively $(15.3 \%$ vs $25.0 \%$ vs $24.3 \% ; P=.289$ ). Nevertheless, about $16 \%$ of arch A patients were managed medically. Previous studies have shown that this can be a realistic treatment option for patients at extreme surgical risk. ${ }^{12,13}$ For AAD patients with primary ET in the arch specifically, the distance between the ET in the arch may result in relatively less pressurization of the false lumen and reduced risk for severe aortic valve regurgitation, dissection extension into the coronary arteries, or pericardial tamponade-particularly when the retrograde false lumen is thrombosed-compared with classic type A dissection with an ET in the ascending aorta. ${ }^{12,13}$ Dissections involving the ascending aorta are not typically candidates for endovascular repair.

In contrast to the arch A group, surgery was associated with a higher in-hospital mortality rate than endovascular or medical treatment in the arch B group $(30.8 \%$ vs $14.3 \%$ vs $13.9 \% ; P=.790$ ). These outcomes cannot be explained by the different prevalence of preoperative complications in the 3 cohorts because these were even higher in the group that was treated endovascularly compared with patients who underwent open surgery $(74.3 \%$ vs $65.4 \%)$. A potential reason for the high surgical mortality in arch B patients may be that open treatment of patients with descending thoracic AAD necessitates adjuncts like cardiac and cerebral protection, which are technically more difficult to perform through a left posterolateral thoracotomy and are associated with higher mortality and morbidity. ${ }^{14-16}$ Technical difficulties might also play a role when a rather proximal arch tear is repaired through a left thoracotomy approach. Alternatively, hybrid procedures through a median sternotomy, with extensive adoption of frozen elephant trunk, have been described for treating dissection of the ascending aorta and arch, showing satisfactory results. ${ }^{17-19}$ However, as the results of the current study show, the surgical approach to dissections with ET in the arch extending to the descending aorta can be associated with poorer results. Although endovascular management of complicated descending dissection is recommended, ${ }^{4,5}$ severe preoperative complications may represent a reason, in some centers, for open surgery. ${ }^{20,21}$

Less invasive management, either endovascular or medical, appears beneficial in patients without ascending aorta involvement, if the situation allows this approach. ${ }^{20-22} \mathrm{In}$ the current study, this is underlined by the shorter median time from diagnosis to intervention in arch A compared with arch B patients ( 4 vs 20 hours; $P<.001$ ), and by the fact that approximately half of the patients in IRAD without ascending aorta involvement were managed medically only. Rylski and colleagues ${ }^{7}$ studied dissections with ET location in the arch but only antegrade extension $(n=22)$ and noted $28 \%$ of patients with medical management and an overall in-hospital mortality of $14 \%$ (compared with $19.3 \%$ in the current study). Rylski and colleagues $^{7}$ also included a cohort with ET location in the descending and retrograde extension into the arch but not ascending aorta $(\mathrm{n}=21)$, and noted initial medical management in $28 \%$ with an in-hospital mortality of $5 \%$. $^{7}$ A previous IRAD report on a cohort with the same characteristics concerning ET location and extension showed that medical management was used in $53.7 \%$, endovascular therapy in $32.8 \%$, and open treatment in $11.9 \%$ of patients, with an overall in-hospital mortality of $10.7 \%{ }^{23}$ In general, these 2 studies and the current study show that ET location in the arch may have worse outcomes than ET in the descending. ${ }^{7,23}$ Although presentation of AAD may need less-aggressive treatment when there is no ascending aorta involvement, the risk of extension of dissection during medical treatment was considerable $(13.8 \%)$ and may have contributed to the relatively high percentage of neurologic deaths in arch type B patients.

The findings of the present study should be viewed in light of its limitations. Patients were not randomized to a predetermined management strategy, and therefore a selection bias was present in the treatments provided. Furthermore, the ETs were not always detectable on imaging studies, and in some patients, multiple ETs were seen. To minimize bias, such patients were excluded from analysis. Moreover, some cases may have been included in which an ascending ET was identified intraoperatively, whereas only an arch tear was visible on preoperative imaging. Because primary entry tear in the arch is rare, a relatively small cohort could be studied. The crude numbers of mortality give a good impression, but do not reach significance for differences between management types within each group. Imaging protocols differed among centers, although imaging was performed by experienced physicians in aortic centers that are typically equipped with state-of-the-art technologies. 
Types of aortic dissection with enty tear in the arch
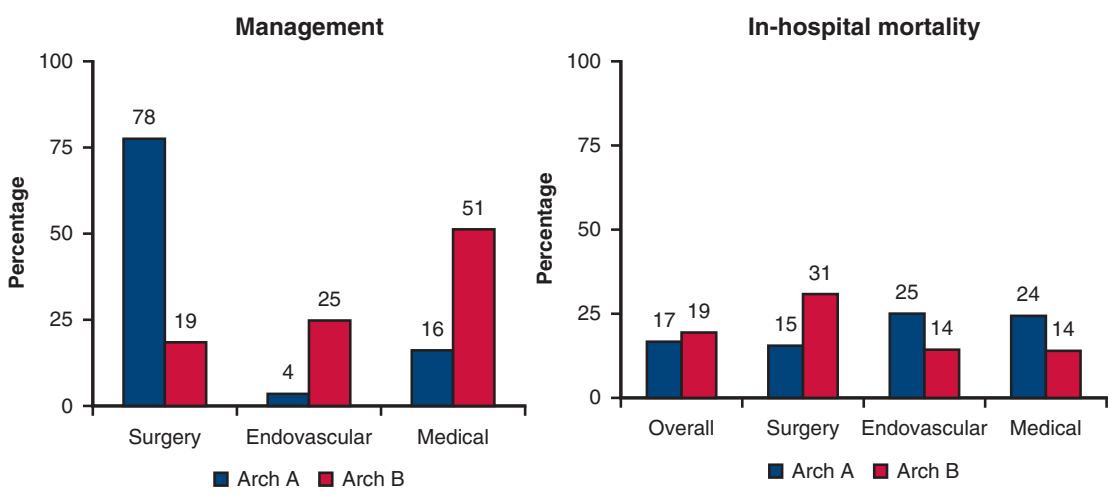

FIGURE 7. Classification, management, and in-hospital mortality of acute aortic dissections with primary entry tear in the arch.

\section{CONCLUSIONS}

Although current guidelines suggest surgical repair for AAD with proximal ET into the arch, IRAD shows that these patients are currently managed by a patient-specific approach (Figure 7). In choosing the management type of this cohort, it may be advisable to stratify AAD based on retrograde or only antegrade extension of the dissection.

\section{Webcast}

You can watch a Webcast of this AATS meeting presentation by going to: https://aats.blob.core.windows.net/ media/18AO/26-br-1545-trimarchi-v2.mp4.

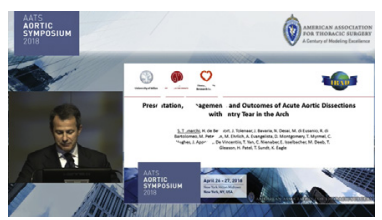

\section{Conflict of Interest Statement}

Authors have nothing to disclose with regard to commercial support.

\section{References}

1. Anagnostopoulos CE, Prabhakar MJ, Kittle CF. Aortic dissections and dissecting aneurysms. Am J Cardiol. 1972;30:263-73.

2. Golledge J, Eagle KA. Acute aortic dissection. Lancet. 2008:372:55-66.

3. Wheat MW Jr. Acute dissecting aneurysms of the aorta: diagnosis and treatment1979. Am Heart J. 1980;99:373-87.

4. Erbel R, Aboyans V, Boileau C, Bossone E, Bartolomeo RD, Eggebrecht H, et al. 2014 ESC guidelines on the diagnosis and treatment of aortic diseases: document covering acute and chronic aortic diseases of the thoracic and abdominal aorta of the adult. The task force for the diagnosis and treatment of aortic diseases of the European Society of Cardiology (ESC). Eur Heart J. 2014;35:2873-926.

5. Hiratzka LF, Bakris GL, Beckman JA, Bersin RM, Carr VF, Casey DE Jr, et al 2010 ACCF/AHA/AATS/ACR/ASA/SCA/SCAI/SIR/STS/SVM guidelines for the diagnosis and management of patients with thoracic aortic disease. A report of the American College of Cardiology Foundation/American Heart Association task force on practice guidelines, American Association for Thoracic Surgery, American College of Radiology, American Stroke Association, Society of Cardiovascular Anesthesiologists, Society for Cardiovascular Angiography and In- terventions, Society of Interventional Radiology, Society of Thoracic Surgeons, and Society for Vascular Medicine. J Am Coll Cardiol. 2010;55: e27-129.

6. Ma WG, Zhang W, Wang LF, Zheng J, Ziganshin BA, Charilaou P, et al. Type A aortic dissection with arch entry tear: surgical experience in 104 patients over a 12-year period. J Thorac Cardiovasc Surg. 2016;151:1581-92.

7. Rylski B, Perez M, Beyersdorf F, Reser D, Kari FA, Siepe M, et al. Acute non-A non-B aortic dissection: incidence, treatment and outcome. Eur J Cardiothorac Surg. 2017;52:1111-7.

8. Hagan PG, Nienaber CA, Isselbacher EM, Bruckman D, Karavite DJ, Russman PL, et al. The international registry of acute aortic dissection (IRAD): new insights into an old disease. JAMA. 2000;283: 897-903.

9. McClure RS, Brogly SB, Lajkosz K, Payne D, Hall SF, Johnson AP. Epidemiology and management of thoracic aortic dissections and thoracic aortic aneurysms in Ontario, Canada: a population-based study. J Thorac Cardiovasc Surg. 2018;155:2254-64.e4.

10. Narayan P, Rogers CA, Benedetto U, Caputo M, Angelini GD, Bryan AJ. Malperfusion rather than merely timing of operative repair determines early and late outcome in type A aortic dissection. J Thorac Cardiovasc Surg. 2017;154:81-6.

11. Parikh N, Trimarchi S, Gleason TG, Kamman AV, di Eusanio M, Myrmel T, et al. Changes in operative strategy for patients enrolled in the international registry of acute aortic dissection interventional cohort program. J Thorac Cardiovasc Surg. 2017;153:S74-9.

12. Nauta FJH, Kim JB, Patel HJ, Peterson MD, Eckstein HH, Khoynezhad A, et al. Early outcomes of acute retrograde dissection from the international registry of acute aortic dissection. Sem Thorac Cardiovasc Surg. 2017;29:150-9.

13. Kim JB, Choo SJ, Kim WK, Kim HJ, Jung SH, Chung CH, et al. Outcomes of acute retrograde type A aortic dissection with an entry tear in descending aorta. Circulation. 2014;130:S39-44.

14. Kim JB, Sundt TM III. Best surgical option for arch extension of type B aortic dissection: the open approach. Ann Cardiothorac Surg. 2014;3: 406-12.

15. Trimarchi S, Nienaber CA, Rampoldi V, Myrmel T, Suzuki T, Bossone E, et al. Role and results of surgery in acute type B aortic dissection: insights from the international registry of acute aortic dissection (IRAD). Circulation. 2006;114: I357-64.

16. Trimarchi S, Nienaber CA, Rampoldi V, Myrmel T, Suzuki T, Mehta RH, et al. Contemporary results of surgery in acute type A aortic dissection: The international registry of acute aortic dissection experience. J Thorac Cardiovasc Surg. 2005; 129:112-22.

17. Di Eusanio M, Pantaleo A, Murana G, Pellicciari G, Castrovinci S, Berretta P, et al. Frozen elephant trunk surgery-the Bologna's experience. Ann Cardiothorac Surg. 2013;2:597-605.

18. Roselli EE, Rafael A, Soltesz EG, Canale L, Lytle BW. Simplified frozen elephant trunk repair for acute DeBakey type I dissection. J Thorac Cardiovasc Surg. 2013;145:S197-201.

19. Shrestha M, Kaufeld T, Beckmann E, Fleissner F, Umminger J, Abd Alhadi F, et al. Total aortic arch replacement with a novel 4-branched frozen elephant trunk prosthesis: single-center results of the first 100 patients. J Thorac Cardiovasc Surg. 2016;152:148-59. 
20. Fattori R, Tsai TT, Myrmel T, Evangelista A, Cooper JV, Trimarchi S, et al. Complicated acute type B dissection: is surgery still the best option? A report from the international registry of acute aortic dissection. JACC Cardiovasc Interv. 2008;1:395-402.

21. Tolenaar JL, van Bogerijen GH, Eagle KA, Trimarchi S. Update in the management of aortic dissection. Curr Treatm Options Cardiovasc Med. 2013;15: 200-13.

22. Fattori R, Montgomery D, Lovato L, Kische S, Di Eusanio M, Ince H, et al. Survival after endovascular therapy in patients with type B aortic dissection: a report from the international registry of acute aortic dissection (IRAD). JACC Cardiovasc Interv. 2013;6:876-82.

23. Nauta FJ, Tolenaar JL, Patel HJ, Appoo JJ, Tsai TT, Desai ND, et al. Impact of retrograde arch extension in acute type $\mathrm{b}$ aortic dissection on management and outcomes. Ann Thorac Surg. 2016;102:2036-43.

Key Words: aortic dissection, acute aortic syndrome, aortic surgery 